\title{
High Performance CNTENFET with K/PPy/CNT nanocomposite biosensing layer for Cholesterol Detection
}

This paper was downloaded from TechRxiv (https://www.techrxiv.org).

\section{LICENSE}

CC BY 4.0

SUBMISSION DATE / POSTED DATE

04-03-2021 / 10-03-2021

\section{CITATION}

Keshwani, Gaurav; Dutta, Jiten Chandra (2021): High Performance CNTENFET with K/PPy/CNT nanocomposite biosensing layer for Cholesterol Detection. TechRxiv. Preprint.

https://doi.org/10.36227/techrxiv.14158292.v1

$\mathrm{DOI}$

10.36227/techrxiv.14158292.v1 


\title{
High Performance CNTENFET with K/PPy/CNT nanocomposite biosensing layer for Cholesterol Detection
}

\author{
Jiten Ch. Dutta ${ }^{1}$ and Gaurav Keshwani ${ }^{2}$ \\ 1,2Department, of Electronics and communication Engineering, Tezpur University, Napaam, Tezpur, Assam \\ 784028, India
}

\begin{abstract}
We have reported a high-performance dual gated carbon nanotube enzyme modified field-effect transistor (CNTENFET) for cholesterol detection. To improve the device performance, we have used dual-gate design with high $\mathrm{k}$ dielectric as top gate and low $\mathrm{k}$ dielectric as bottom gate and a nanocomposite of potassium doped carbon nanotube with polypyrrole (K/PPy/CNT) as the biosensing membrane. The device exhibited a good sensitivity $(\sim 1.0 \mathrm{~V} /$ decade), low response time $(\sim 1 \mathrm{~s})$, wide dynamic range $(0.1-25) \mathrm{mM}$, wide linear range $(2-20 \mathrm{mM})$, low detection limit $(0.11 \mathrm{mM})$, good stability $(7$ months $)$ and high selectivity (interference $\sim 1.8 \%$ ).
\end{abstract}

Index Terms— Carbon nanotube (CNT), cholesterol, dual-gate, ENFET, K/PPy/CNT.

\section{INTRODUCTION}

Carbon nanotube based ENFETs have been found as ideal biosensor with high selectivity, real-time response and have capability of label free detection [1], [2]. Polyethylenimine (PEI) doped carbon nanotubes as channel material exhibit excellent n-type FET characteristics and has advantages over other types of n-doping techniques [3], [4]. The response time, selectivity, stability and dynamic range of ENFET devices depend on the number of enzyme molecules and therefore, immobilization of enzyme on the top of the inorganic gate insulator layer of ISFET is a crucial step. Various advanced materials such as CNT, gold nanoparticles and porous materials have been used for firmed immobilization of the enzyme. In general, these materials cannot support enzyme directly, and hence selection of an enzyme-loaded matrix compatible to both the insulating layer and the enzyme has importance in ENFET construction. Nanocomposite of potassium doped carbon nanotube with polypyrrole $(\mathrm{K} / \mathrm{PPy} / \mathrm{CNT})$ is suitable to use as bio-sensing layer for its high compatibility with enzyme, fast electron transfer and better dispersion [5]. The sensitivity of ENFET device is an important factor for molecular detection [6], [7]. The sensitivity of single gate ENFET beyond the Nernstian sensitivity limit (usually $59 \mathrm{mV} / \mathrm{pH}$ at room temperature) can be enhanced by introducing double gates in the device structure [8]. Sensitivity of such dual gate ENFET is dependent on the capacitive coupling between the top gate and bottom gate dielectrics that can be increased by using high- $\kappa$ dielectric as top gate material and low- $\kappa$ dielectric as bottom gate material [9].

Referring to cholesterol biomolecule, it is an essential steroid metabolite found in most of the human cells and is carried through blood by lipoproteins [10]. It contributes to the structure of cell walls, helps in synthesis of bile acids in the intestine, allows the body to produce vitamin $\mathrm{D}$ and enables the body to make steroid hormones. However, elevated level of cholesterol is a biomarker for myocardial infarction, type 2 diabetes, thrombosis, high blood pressure and cardiovascular diseases [11]. Therefore, development of a low cost, integrated, disposable and reliable technique for its detection is essential and significant in medical and clinical applications.

ENFET is constructed by immobilizing an enzyme on the top of the gate insulator of an ion sensitive field effect transistor (ISFET). The Simplest physics picture behind the working of ENFET is the exploitation of field effect concept introduced by an electrolyte gate electrode, which is capacitively coupled through a thin dielectric layer with semiconducting channel. The enzyme reacts with the analyte of interest and generates or consumes protons which changes charge at the gate surface in accordance with site binding theory. This change in charge at the gate surface modulates the channel conductance and hence the channel current between the source and the drain of the ISFET. This output current can be related with the concentration of analyte under examination. In case of ChOx enzyme, for an example, it reacts with cholesterol in accordance with the following chemical scheme:

$$
\begin{gathered}
\text { Cholesterol }+\mathrm{O}_{2} \stackrel{\mathrm{ChO}_{\mathrm{X}}}{\longrightarrow} \text { Cholest-4-en -3-one }+\mathrm{H}_{2} \mathrm{O}_{2} \text {; } \\
\mathrm{H}_{2} \mathrm{O}_{2} \rightarrow \mathrm{O}_{2}+2 \mathrm{H}^{+}+2 \mathrm{e}^{-}
\end{gathered}
$$


The number of released protons $\left(\mathrm{H}^{+}\right.$ions) depends on concentration of electrolyte solution and are accepted by the insulating surface as per its buffer capacity. Acceptance of protons by the surface affects the electrolyte - insulator interface potential $\left(\psi_{0}\right)$ and therefore, modulates the channel current.

In this letter, we have reported a high-performance carbon nanotube enzyme modified field-effect transistor(CNT-ENFET) for cholesterol detection with good sensitivity $(\sim 1 \mathrm{~V} /$ decade), low detection limit $(0.11 \mathrm{mM})$, good stability (7 months) and high selectivity (interference $\sim 1.8 \%$ ). To our knowledge, these are the best characteristics parameters that have been reported so far.

\section{DUALGATECNTENFET}

\section{A. Fabrication}

Fabrication of the dual gate CNT-ENFET has started with indium tin oxide (ITO) coated glass plate (dimension: $6 \mathrm{~mm} \times 3 \mathrm{~mm} \times 1.1$ $\mathrm{mm})$ as a substrate which has also served as the bottom gate. On the top of the ITO, a layer of $\mathrm{ZnO}(\kappa \sim 1.5)$ has been deposited (dimension: $5 \mathrm{~mm} \times 3 \mathrm{~mm} \times 10 \mathrm{~nm}$ ) using electrochemical deposition (ECD) technique [12]. On the top of this bottom insulating layer, a thin film of PEI doped multi-walled carbon nanotube (MWCNT) (> $8 \%$ carboxylic acid functionalized, avg. dia. $9.5 \mathrm{~nm}$, length $1.5 \mathrm{~nm}$ ) has been deposited (dimension: $5 \mathrm{~mm} \times 3 \mathrm{~mm} \times 10 \mathrm{~nm}$ ) by ECD technique. This CNT layer forms the $\mathrm{n}+$ source (S), drain (D), and channel regions. A high $\kappa$ dielectric $\mathrm{ZrO}_{2}(\kappa \sim 25)$ layer has been then deposited on the top of the CNT layer (dimension: $3 \mathrm{~mm} \times 3 \mathrm{~mm} \times 10$ $\mathrm{nm}$ ) to act as top gate. Metal $\mathrm{Al}$ has been used to form the source (S) and drain (D) contact regions on the top of the CNT layer. The details of fabrication process of these layers and contacts can be obtained in our earlier publications [12], [13]. Referring to the nanocomposite $\mathrm{K} / \mathrm{PPy} / \mathrm{CNT}$ layer, a solution has been first prepared by adding two $\mathrm{ml}$ of $(1.0 \mathrm{M}) \mathrm{KOH}$ solution (potassium cannot be directly doped as it is unstable in air and very reactive with water) to $10 \mathrm{ml}$ of CNT solution. Pyrrole solution $(8 \mu \mathrm{l})$ prepared in formic acid with $10 \mu \mathrm{l}$ $\mathrm{K}$-doped CNT solution has then been added in $10 \mathrm{ml}$ acetonitrile. The solution has then been sonicated for 20 minutes and kept idle for 12 hours. This complex solution has then been deposited on top of the $\mathrm{ZrO}_{2}$ layer by spin coating technique to form nanocomposite $\mathrm{K} / \mathrm{PPy} / \mathrm{CNT}$ layer (dimension: $3 \mathrm{~mm} \times 3 \mathrm{~mm} \times 10 \mathrm{~nm}$ ). After the fabrication of the device, $10 \mu \mathrm{L}$ of $\mathrm{ChO}_{\mathrm{x}}(\sim 24 \mathrm{U} / \mathrm{mg}$ activity in PBS $)$ solution has been immobilized (as per experimental results which is not shown) on the top of the sensing layer by physical adsorption technique for experimentation [14].

\section{B. Characterization}

Prior to being used as ENFET, the device has been biased for electrical characterization. Conventionally, for single gate operating mode, the bottom gate (BG) is grounded, whereas the top gate (TG) is grounded for double gate operation [15]. Using this methodology, TG voltage $\left(\mathrm{V}_{\mathrm{GS}(\mathrm{T})}\right)$, BG voltage $\left(\mathrm{V}_{\mathrm{GS}}(\mathrm{B})\right)$ and drain voltage $\left(\mathrm{V}_{\mathrm{DS}}\right)$ have been fixed at $0.6 \mathrm{~V}, 1.0 \mathrm{~V}$ and $0.3 \mathrm{~V}$ respectively as shown in Fig.1.
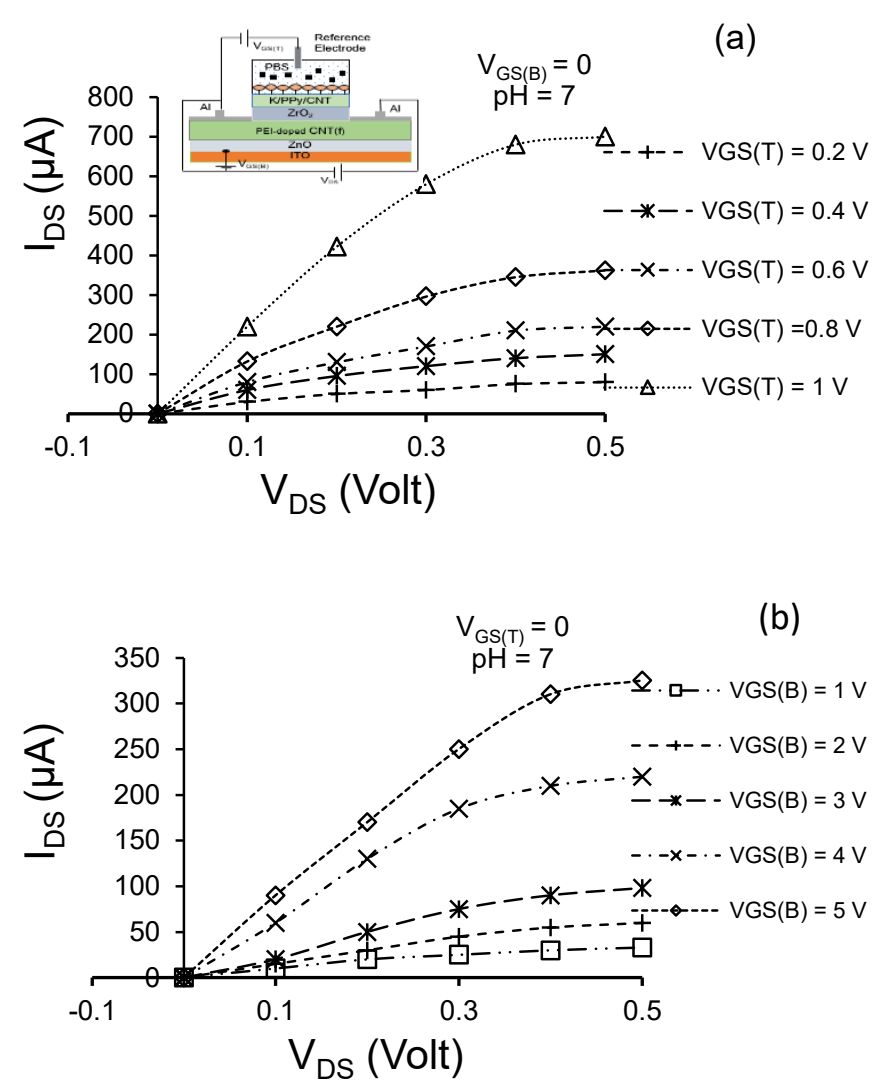

Fig. 1. (a) Output characteristics of TG CNTENFET at $\mathrm{pH}$ 7. The inset shows a schematic diagram of the ENFET structure. (b) The output characteristics of BG ENFET at $\mathrm{pH} 7$.

\section{Sensor Characteristics}

In order to determine the sensor characteristics, cholesterol stock solutions of different concentrations $(0.1 \mathrm{mM}$ to $25 \mathrm{mM})$ have been prepared using Triton $\mathrm{X}-100$ as surfactant (as cholesterol is insoluble in water, therefore, need to be blended maintaining some processes). The output characteristics at different concentrations and linearity curve of the device are shown in fig. 2(a) and (b) respectively. From fig.2(a), it is observed that the dynamic range of the device is $(0.1-25) \mathrm{mM}$ and from fig.2(b) it is observed that the device is linear from $2 \mathrm{mM}$ to $20 \mathrm{mM}$ with regression coefficient 0.994 . The current sensitivity has been found to be $\sim 75.17$ $\mu \mathrm{A} / \mathrm{mM}$.

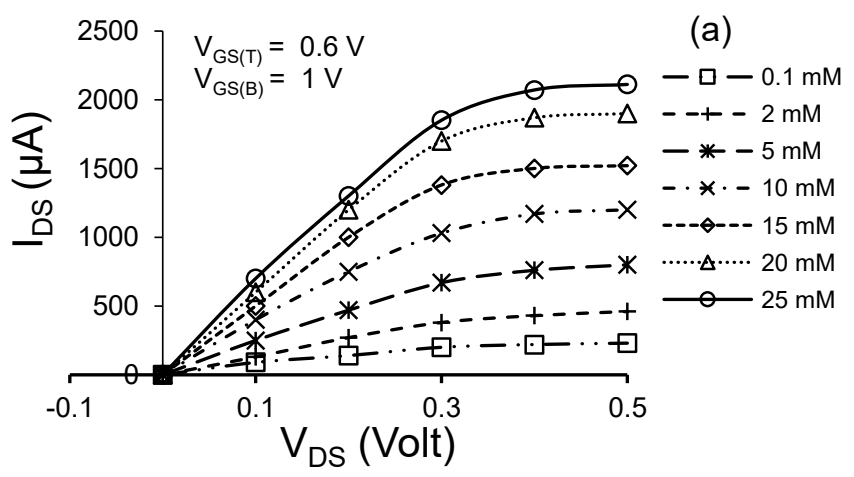




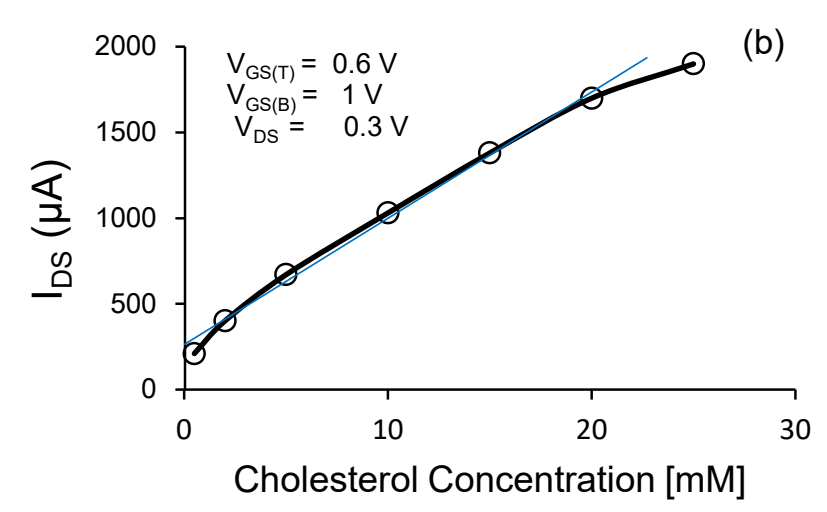

Fig. 2. (a) Output characteristics of the dual gated CNT-ENFET. (b) The linearity curve of the device with regression coefficient 0.994 .

ENFET being an electronic device basically measures the insulatorelectrolyte interface potential, $\psi_{0}$ which is a function of solution $\mathrm{pH}$ dependent on concentration of solution. In general, for single gate CNT-ENFET, $\psi_{0}$ is related with its threshold voltage $\mathrm{V}_{\text {TH(ENFET) by }}$ (2):

$$
V_{T H(E N F E T)}=E_{r e f}-\psi_{0}+\chi^{s o l}-\frac{\phi_{C N T}}{q}-\frac{Q_{t o t a l}}{C_{\text {insulator }}}
$$

Unlike MOSFET, the threshold voltage of ENFET varies with respect to the concentration of the analyte and therefore the sensitivity of the device can be expressed as:

$$
S=\frac{\Delta V_{T H(E N F E T)}}{\Delta C}
$$

Where, $\Delta C$ is the change in electrolyte concentration and $\Delta V_{T H(E N F E T)}$ is the corresponding change in threshold voltage of ENFET. The change in threshold voltage for different concentrations of analyte can be determined experimentally from transfer characteristic curves of ENFET using extrapolation in linear region (ELR) technique [16]. Using this technique (fig.3.a), the change in $\mathrm{V}_{\text {TH(ENFET) with respect to cholesterol concentration has been plotted }}$ in fig.3(b). The slope of this curve gives the sensitivity of the device and found to be $1.0 \mathrm{~V} /$ decade. Limit of detection has been calculated using basic equation [17] and found to be $0.11 \mathrm{mM}$. Temperature dependence of the device has been tested and maximum response has been obtained at $30^{\circ} \mathrm{C}$ in the temperature range of 20 to $40^{\circ} \mathrm{C}$.
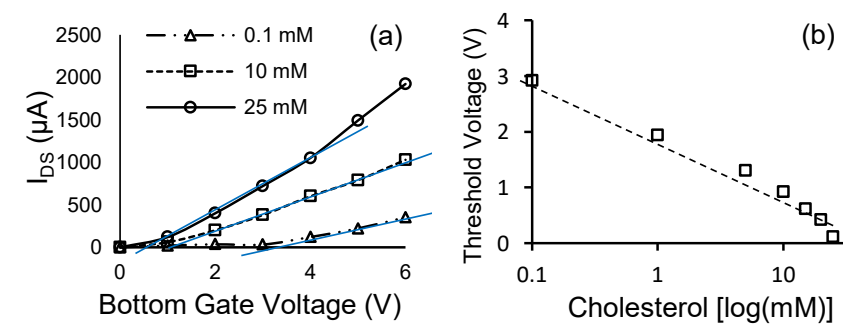

Fig. 3. (a) Extraction of threshold voltage from transfer characteristic curves using ELR technique. (b) Threshold voltage variation with respect to cholesterol concentration.
The specificity of the sensor has been studied by testing the device for interference of other biomolecules (fig. 4(a)). It was found that the interference of the device is negligible with other biomolecules such as glucose, uric acid, urea etc. The interference percentage has been calculated using (4) [20] and found to be $\sim 1.8 \%$.

$$
\% \text { Interference }=\frac{I_{\text {chol }}-I_{\text {int }}}{I_{\text {chol }}} \times 100
$$

For testing the stability of the device, the device has been tested few times every month over a period of 8 months and then curve has been plotted taking IDs as a parameter. It is observed that the device is stable over a period of 7 months (fig. 4(b)). The reproducibility of the device has been proven by performing experiments with five fabricated devices under similar conditions. All the five devices have produced almost similar results. The repeatability test has been performed on the same device for 10 times (once a week) and almost similar results have been found. The fabricated sensor has been compared with other FET based cholesterol sensors available in the literature and shown in table I.
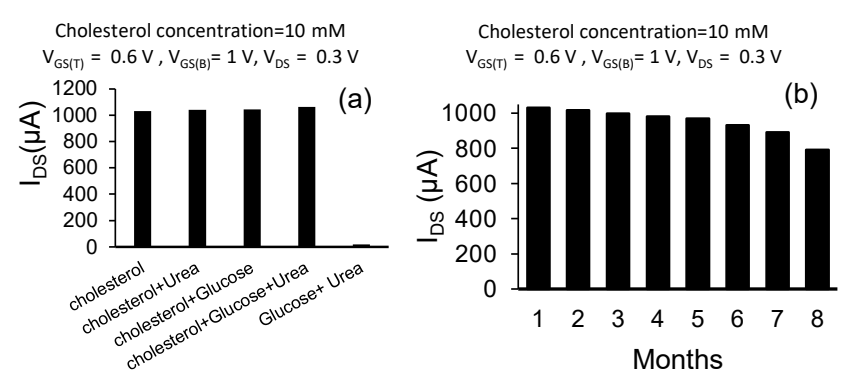

Fig. 4. (a) Interference of cholesterol with other biomolecules. (b) The stability of the device

Table 1. Comparison of different ENFET biosensors developed for cholesterol detection

\begin{tabular}{llllll}
\hline \hline Ref. & $\begin{array}{c}\text { Bio sensing } \\
\text { layer }\end{array}$ & $\begin{array}{l}\text { Linearity } \\
(\mathrm{mM})\end{array}$ & $\begin{array}{l}\text { LOD } \\
(\mathrm{mM})\end{array}$ & Sensitivity & $\begin{array}{l}\text { Shelf } \\
\text { Life } \\
(\text { Day })\end{array}$ \\
\hline$[19]$ & $\begin{array}{l}\text { ZnO NRS } \\
\text { Ferrocenyl/ }\end{array}$ & $0.001-45$ & $5 \times 10^{-5}$ & $10 \mu \mathrm{A} \mathrm{cm}^{-2} \mathrm{mM}^{-1}$ & - \\
{$[20]$} & $1.8-12.9$ & & $57 \mathrm{mV} /$ decade & - \\
$\begin{array}{l}{[18]} \\
\text { alkanethiol }\end{array}$ & PANI/ZnO & $0.5-16.6$ & 0.25 & $60 \mathrm{mV} /$ decade & 150 \\
$\begin{array}{l}\text { This } \\
\text { work }\end{array}$ & $\mathrm{K} / \mathrm{PPy} / \mathrm{CNT}$ & $2-20$ & 0.11 & $1 \mathrm{~V} /$ decade & 210 \\
\hline \hline
\end{tabular}

\section{CONCLUSION}

We have presented a high-performance CNT-ENFET with $\mathrm{K} / \mathrm{PPy} / \mathrm{CNT}$ nanocomposite as sensing layer for cholesterol detection. Due to the use of K/PPy/CNT nano composite, the sensor has shown high dynamic range, low detection limit and good stability. Owing to the use of double gates, the resulting biosensor has shown high sensitivity which is desirable for nanobiosensing applications such as measurement of proteins 
interactions, protein function, antibody-antigen reactions, DNA hybridization etc. Also the fabricated device has been found to be reproducible and repeatable with negligible interference. Hence, dual gated CNT-ENFET with $\mathrm{K} / \mathrm{PPy} / \mathrm{CNT}$ nano composite as sensing layer could be a valuable platform for cholesterol detection.

\section{ACKNOWLEDGMENT}

The authors thank the Ministry of Electronics and Information Technology (MeitY), Government ofIndia for the support through Visvesvaraya $\mathrm{PhD}$ scheme.

\section{REFERENCES}

[1] Allen B L, Kichambare P D, Star A (2007), “Carbon nanotube field-effecttransistor-based biosensors,"Advanced Materials, vol. 19, no.11, pp. 1439-1451.

[2] Chen K I, Li B R, Chen Y T (2011), "Silicon nanowire field-effect transistor-based biosensors for biomedical diagnosis and cellular recording investigation," Nano today, vol. 6, no.2, pp. 131-154.

[3] Shim M, Javey A, Shi Kam N W \& Dai H (2001), "Polymer functionalization for air-stable n-type carbon nanotube field-effect transistors," Journal of the American Chemical Society, vol. 123, no. 46, pp. 11512-11513.

[4] Sablok K, Bhalla V, Sharma P, Kaushal R, Chaudhary S, \&Suri C R (2013), “Amine functionalized graphene oxide/CNT nanocomposite for ultrasensitive electrochemical detection of trinitrotoluene," Journal of hazardous materials, vol. 248, pp. 322-328.

[5] Singh K, Solanki P R, Basu T, \& Malhotra B D (2012), "Polypyrrole/multiwalled carbon nanotubes-based biosensor for cholesterol estimation," Polymers for Advanced Technologies, vol. 23, no. 7, pp. 1084-1091.

[6] Spijkman M, Smits E C P, Cillessen J F M, Biscarini F, Blom P W M, \& De Leeuw D M (2011),"Beyond the Nernst-limit with dual-gate $\mathrm{ZnO}$ ion-sensitive field-effect transistors," Applied Physics Letters, vol. 98, no. 4, Art. no. 043502.

[7] Liu S, \&Guo X (2012), "Carbon nanomaterials field-effect-transistor-based biosensors,"NPG Asia Materials, vol. 4, no. 8, pp. e23-e23.

[8] Jang H J, \& Cho W J (2012), "Fabrication of high-performance fully depleted silicon-on-insulator based dual-gate ion-sensitive field-effect transistor beyond the Nernstian limit," Applied Physics Letters, vol. 100, no.7, Art. no. 073701.

[9] Jang H J, Bae T E, \& Cho W J (2012), "Improved sensing performance of polycrystalline-silicon based dual-gate ion-sensitive field-effect transistors using high-k stacking engineered sensing membrane," Applied Physics Letters, vol. 100, no. 25 , Art. no. 253703

[10] Narwal V, Deswal R, Batra B, Kalra V, Hooda R, Sharma M, \& Rana J S (2019), Cholesterol biosensors: A review. Steroids, vol. 143, pp. 6-17.

[11] Malarvizhi A, \&Pandurangan A (2012),"Bonding of cholesterol oxides to functionalisedmultiwalled carbon nanotubes for in-vitro biosensor application"

[12] Dutta J C, \& Thakur H R (2017), "Sensitivity determination of CNT-based ISFETs for different high-dielectric materials," IEEE Sensors Letters, vol. 1, no. (2), pp. 14.

[13] Dutta J C, Thakur H R, \& Keshwani G (2019),"High-Performance Dual-Gate Carbon Nanotube Ion-Sensitive Field Effect Transistor With High-\$kappa \$ Top Gate and Low-\$kappa \$ Bottom Gate Dielectrics," IEEE Sensors Journal, vol. 19, no. (14), pp. 5692-5699.

[14] Karajanagi S S, Vertegel A A, Kane R S\&Dordick J S (2004), Structure and function of enzymes adsorbed onto single-walled carbon nanotubes," Langmuir, vol. 20, no. (26), pp. 11594-11599.

[15] Lu C H, Hou T H \& Pan T M (2017), "High-Performance Double-Gate \$lalpha \$InGaZnO ISFET pH Sensor Using a HfO2 Gate Dielectric," IEEE Transactions on Electron Devices, vol. 65, no. (1), pp. 237-242.

[16] Ortiz-Conde A, Sánchez F G, Liou J J, Cerdeira A, Estrada M \& Yue Y (2002), “A review of recent MOSFET threshold voltage extraction methods," Microelectronics reliability, vol. 42, no. 4-5, pp. 583-596.

[17] Goswami, P (2020), Advanced Materials and Techniques for Biosensors and Bioanalytical Applications, 1st ed., CRC Press: Boca Raton, FL, USA, ISBN 9781003083856.

[18] Barik M A, \& Dutta J C (2014), "Fabrication and characterization of junctionless carbon nanotube field effect transistor for cholesterol detection," Applied Physics Letters, vol. 105, no. 5, Art. no. 053509.

[19] Ahmad R, Tripathy N, \& Hahn Y B (2013), "High-performance cholesterol sensor based on the solution-gated field effect transistor fabricated with ZnOnanorods," Biosensors and Bioelectronics, vol. 45, pp. 281-286.

[20] Ishige Y, Shimoda M, \&Kamahori M (2009)."Extended-gate FET-based enzyme sensor with ferrocenyl-alkanethiolmodified gold sensing electrode," Biosensors and Bioelectronics, vol. 24, no. 5, pp. 1096-1102. 